\title{
Reproduction and Ecology of the Hermaphroditic Cockle Clinocardium nuttallii (Bivalvia: Cardiidae) in Garrison Bay*
}

\author{
V. F. Gallucci ${ }^{1 \cdot}$ and B. B. Gallucci ${ }^{2}$ \\ ${ }^{1}$ School of Fisheries and Center for Quantitative Science in Forestry, Fisheries, and Wildlife, University of Washington, Seattle, \\ Washington 98195 , USA \\ ${ }^{2}$ Department of Physiological Nursing, University of Washington, Seattle, Washington 98195, and Pathology, Fred Hutchinson \\ Cancer Research Center, Seattle, Washington 98101, USA
}

\begin{abstract}
In this first description of the hermaphroditic reproductive cycle of the cockle Clinocardium nuttallii, male and female follicles are shown to develop in phase with each other The gametes of both sexes are spawned about the same time. The cockles in Garrison Bay spawn from April to November, usually in the second year, but for a small segment of the stock there is the potential to spawn in the first year of life. Density, growth rate, patterns of mortality and other ecological factors are discussed in relation to the evolution of bisexual reproduction. The central driving forces toward bisexual reproduction are the combination of environmental unpredictability and predatory pressure, where no refuge in size exists to guide the allocation of energy between reproduction and growth.
\end{abstract}

\section{INTRODUCTION}

Recent reviews have summarized the possible selective advantages of hermaphroditism (Ghiselin, 1969 Bawa, 1980) but its role in the structure of benthic communities, particularly bivalve communities, is poorly understood. This is surprising in view of the well known diversity of reproductive strategies followed by oysters, scallops, and other bivalves. In this paper we present for the first time the annual reproductive cycle and associated ecological aspects of the bivalve Clinocardium nuttallii (Conrad, 1837).

Clinocardium nuttallii - also known as basket cockle, heart cockle, or Pacific cockle - is found from the Bering Sea to San Diego (Quayle, 1960). Generally it occurs in bays and straits where the surf is subdued, in sediments ranging from coarse sand to silt/clay, and from shallow subtidal to intertidal areas. In Garrison Bay the cockle is abundant at low to medium levels

- Contribution No. 569, Center for Quantitative Science (HR20), College of Ocean and Fishery Sciences, School of Fisheries, University of Washington, Seattle, Washington 98195, USA

- Addressee for reprint requests (about $-2.0 \mathrm{ft}[-0.61 \mathrm{~m}]$ to $+3.0 \mathrm{ft}[0.92 \mathrm{~m}]$ ) of the intertidal region and in sediment varying from silt/clay (closed end of bay) to coarse sand (open end of bay) (Fig. 1). The clam lives generally at the surface or just below the surface of the sediment. In this respect it is different from most of the other 9 common bivalves in Garrison Bay which are usually found at depths of a few $\mathrm{cm}$ to $1 \mathrm{~m}$ below the sediment surface.

Despite the general availability of the Pacific cockle, its occasional harvest by recreational clam diggers and its frequent occurrence on faunal lists, this cockle has received little scientific attention. By contrast, the growth and reproductive cycles of the European cockles - Cardium ( = Cerastoderma) edule and Cardium glaucum - are well known. C. edule and C. glaucum have similar dioecious reproductive cycles (Rygg, 1970; Boyden, 1971; Kingston, 1974). Gametogenesis is initiated in the fall and proceeds rapidly in the spring; spawning takes place as early as May for $C$. edule, and as late as July for C. glaucum, in areas where they cooccur. Gonadal maturity was determined by histologic methods (Kingston, 1974) by the microscopic examination of gonadal smears and by the macroscopic or visual examination of the gonads (Boyden, 1971). 
The first report of hermaphroditism in Clinocardium nuttallii (Edmondson, 1920) noted only that in Oregon both male and female follicles can be discerned in the spring, both ova and spermatozoa develop through the summer, and spawning occurs in mid to late September. Fraser (1931), in the second report on this subject, noted that in the vicinity of Vancouver Island (Canada) spawning occurred in late spring and extended over several weeks, and that sexual maturity occurred in the second year More recently, Quayle (1960) and Quayle and Bourne (1972), writing for 'interested laymen' also noted the bisexuality of the cockle and stated that sexual maturity occurs in the second year. None of the papers cited gives histological details, although Edmondson (1920) provides one sketch of a sperm follicle surrounded by three ovarian follicles.

This paper describes the hermaphroditic reproductive cycle of Clinocardium nuttallii by distinguishing 5 grades of development of male and female follicles. and provides criteria relating a visual (macroscopic) evaluation of gonad fullness to the histologic grade. Our data indicate that gametogenesis may be initiated in any month except July, August and September, while spawning takes place from April to November. Finally, we explore the associated ecological factors surrounding the Pacific cockle and address the larger question of why bisexuality is an advantageous reproductive strategy.

\section{MATERIALS AND METHODS}

Clinocardium nuttallii were collected in Garrison Bay (Fig. 1), a small embayment on San Juan Island, Washington, USA (Lat. $48^{\circ} 35^{\prime} \mathrm{N}$ - Long. $128^{\circ} 08^{\prime} \mathrm{W}$ ). Intertidal bivalves were sampled from September 1975 to October 1976 during low tides which occur bimonthly. The samples were collected monthly during November, December and January, and bimonthly in all other months. The samples were taken over the full length of the east side of the bay from the open to the closed ends. The bay is roughly partitioned into 3 areas (Fig. 1): the southern, closed end of the bay, with a silt/clay sediment, the northern, open end of the bay, with coarse/compact sand, and the central area between these extremes with a heterogeneous sediment more similar to the silt/clay type. Scherba and Gallucci (1976) have given sediment particle-size analyses and a pattern of occurrence of bivalves and polychaetes by area and by season. Particle size data were supplemented by Rawson (1980).

Bivalves were collected by a stratified random sampling plan in which 5 strata were defined parallel to the water line in $100 \mathrm{~m}$ long sub-sections. Each

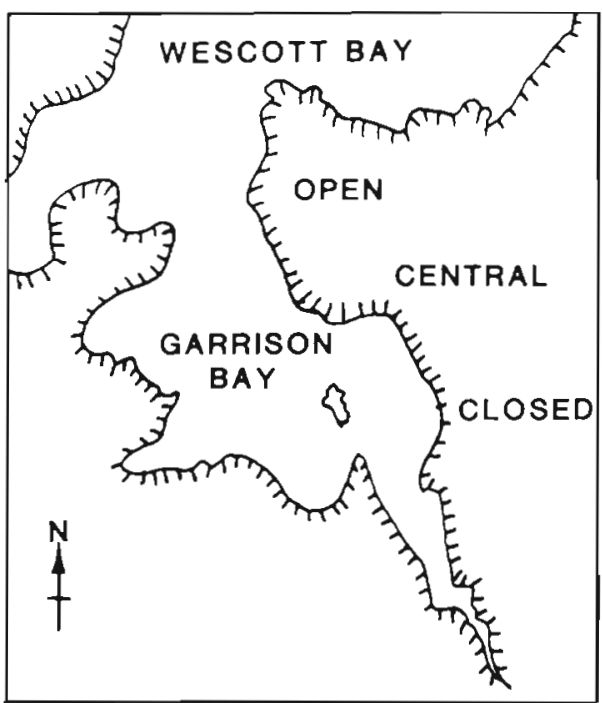

Fig. 1. Sampling areas in Garrison Bay

stratum was $20 \mathrm{ft}(6.82 \mathrm{~m})$ wide, dividing the intertidal from low to high tide, $-2.0 \mathrm{ft}(-0.61 \mathrm{~m})$ to $8 \mathrm{ft}(2.44 \mathrm{~m})$ (Fig. 1). The sample unit was a square frame $0.38 \mathrm{~m}$ on a side. All the substrate enclosed by the frame was sieved through a screen of $5 \mathrm{~mm}$ mesh. During each sampling period 5 to 8 sample units were generally taken per stratum. Over the sampling period 368 cockles were removed and examined from the 18,144 clams collected from 782 sample units. Although not all the sample units contained cockles, all of the clams were used, either for other reproductive studies or as part of an ongoing bivalve management project in Garrison Bay; see Gallucci and Rawson (1979) for a more complete discussion of sampling methods, management plan, and for other details.

Bivalves from each sample unit were kept in separate bags, returned to the Friday Harbor Laboratories, placed in seawater tables, and processed within a few hours. Processing consisted of recording the sample unit location, the bivalves contained therein, and their dimensions. In this paper we report the dimension of length which was measured more or less parallel to the hinge at the maximum anterior-posterior distance. All measurements were made with a vernier-caliper to $0.1 \mathrm{~mm}$. Then all of the cockles in each stratum per area were pooled and at least half were opened and a stage assigned to indicate (from their visual or macroscopic appearance) the ripeness of the gonad. In total, 257 cockles were visually examined, 45 were randomly sub-sampled for histologic study and a microscopic grade was assigned. If there were over 6 cockles per stratum per day, then at least one-half of the cockles were randomly chosen for visual staging from different identifiable size classes; otherwise all of the cockles were staged. 


\section{Visual Examination of Gonads}

In each size class, the valves of the cockles were opened, the foot was cut longitudinally and the gonadal tissue examined. A stage of 0 was assigned when no gonadal tissue was seen, a stage of 1 when some tissue was noted and a stage of 2 for a full gonad. Photographs were taken for documentation and for comparison of month-to-month samples.

\section{Microscopic Grading of Gonads}

Forty-five of the cockles that were visually graded were also fixed in Bouin's solution and preserved in $70 \%$ alcohol. A slice of tissue was removed along the midline from the umbo area to the foot. A 2-mm block was taken from each specimen, carried through an alcohol series, embedded in paraffin, sectioned at 5-7 $\mu \mathrm{m}$, and stained with Harris hematoxylin and counterstained with eosin

The classification of grades described below is modified from one used to classify Cardium spp. (Kingston, 1974).

\section{RESULTS}

\section{Distribution}

The density of Clinocardium nuttallii depends upon intertidal height, month of sampling, and area of the bay. Closed (south) end density is highest and north (open) end density lowest. Central area density in August 1976 was estimated by stratified systematic sampling to be $12.98 \pm 1.39$ cockles $\mathrm{m}^{-2}$ in a stratum just below the zero tidal level, $4.93 \pm 0.97{\text { cockles } \mathrm{m}^{-2}}^{-2}$ in the stratum surrounding the zero tidal level, and zero in the higher strata. Zero density is due to a higher mortality rate from predation and temperature stress. Generally speaking, the spatial pattern of occurrence of any organism is associated with its life history strategy, a common association being a clustered distribution to facilitate reproduction and/or feeding success. For $C$. nuttallii the evidence is mixed for a clustered pattern because the null hypothesis that the pattern is random, and thus not contagious, is rejected at most tidal levels at $\alpha=0.05$ (Elliott, 1971). Gallucci and Geiszler (in preparation) discuss in detail the ecological factors contributing to the density and spatial distribution estimates.

The number of cockles sampled for visual stage and sub-sampled for microscopic grade by area of occurrence was:

\begin{tabular}{lrrc} 
Area & Number & Visual & Microscopic \\
\hline Closed & 239 & 174 & 27 \\
Central & 70 & 52 & 7 \\
Open & 59 & 31 & 11 \\
\hline Total & 368 & 257 & 45
\end{tabular}

\section{Microscopic Examination of Gonads}

Of the cockles $100 \%$ were hermaphroditic, i.e. both male and female follicles were present in all specimens examined. The classification scheme for gonadal maturity in Clinocardium nuttallii was modified from one devised for $C$. edule and C. glaucum (Kingston, 1974). In C. nuttallii male and female follicles in each specimen were considered separately. Generally, there was more than one developmental grade for each sex per individual, and both male and female follicles tended to have the same microscopic grades. The 5 grades are associated with the following characteristics.

\section{Grade 1 - Initiation of gametogenesis (Fig. 2a, 2b)}

Female: Both oogonia and a few oocytes lined the follicle. Male: Spermatogonia, primary and secondary spermatocytes partially lined the follicle wall. In both, follicles were generally collapsed. There were usually no residual gametes from the previous spawning cycle.

\section{Grade 2 - Developing gametes (Fig. 2c)}

Female: Rounded oocytes along with many pear shaped oocytes were attached to the follicle wall. One or 2 detached oocytes were present. The walls between some follicles were broken, so that these follicles appeared larger than in Grade 1 and the oocytes appeared more widely spaced. Male: Spermatocytes and spermatids predominated. Less than one third of the follicle was filled with spermatozoa.

$$
\text { Grade } 3 \text { - Ripe (Fig. 2d) }
$$

Female: Some oocytes remained attached to the follicle wall. Many of the oocytes were free within the follicle. Male: The follicle was more than two thirds full with spermatozoa. The spermatozoa were arranged in characteristic bands.

$$
\text { Grade } 4 \text { - Recently spawned (Fig. 2e) }
$$

Female: The follicle contained an occasional free oocyte, and moderate amounts of oocytes were still 

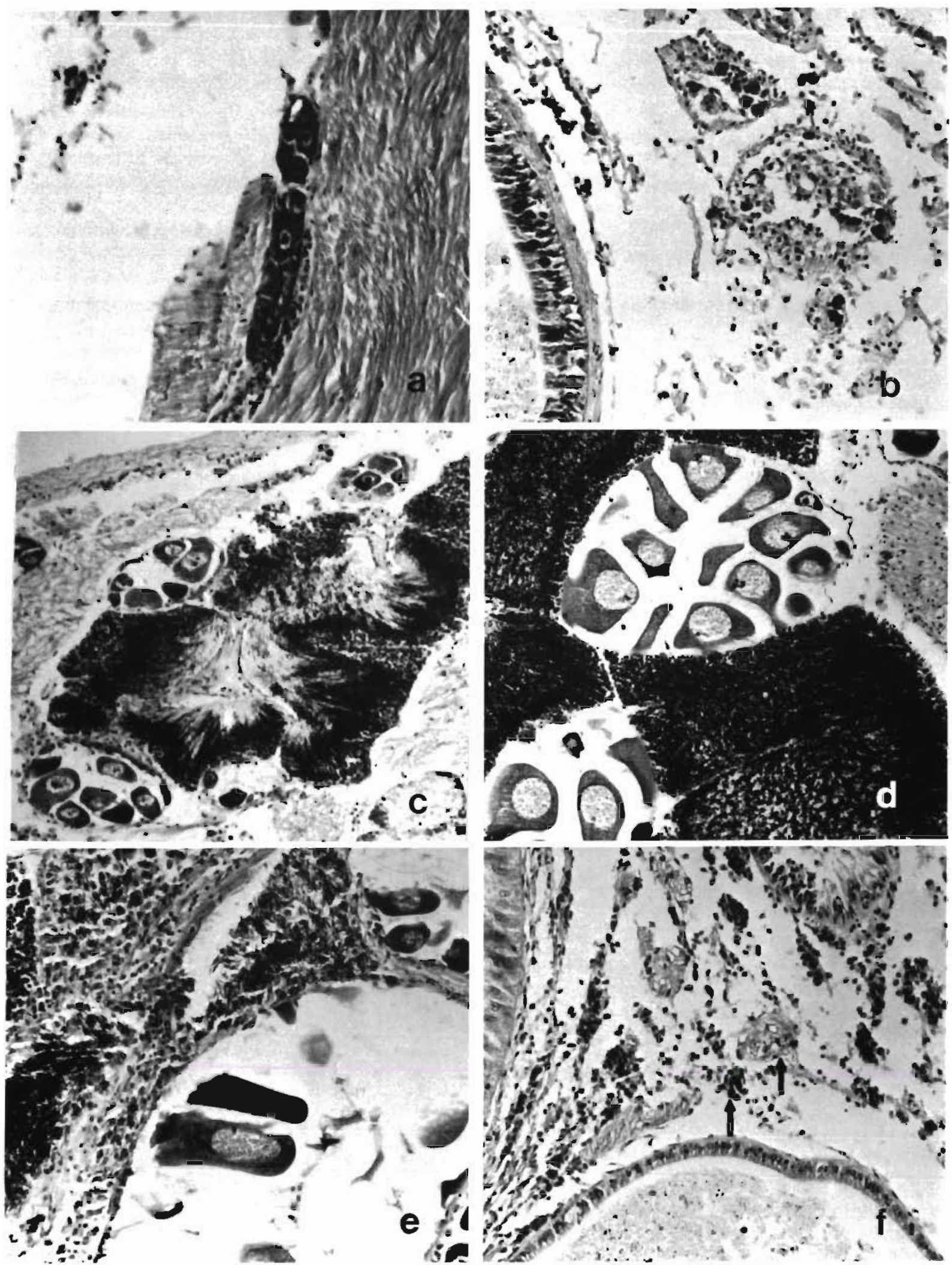

Fig. 2. Clinocardium nuttallii. Photomicrographs of male and female follicle development. (a) female follicles, Grade 1 ; (b) male follicles, Grade 1; (c) male and female follicles, Grade 2; (d) male and female follicles, Grade 3; (e) male and female follicles, Grade $4 ;$ (f) male and female follicles (arrows), Grade 5. All magnifications between 200 and 300 times 


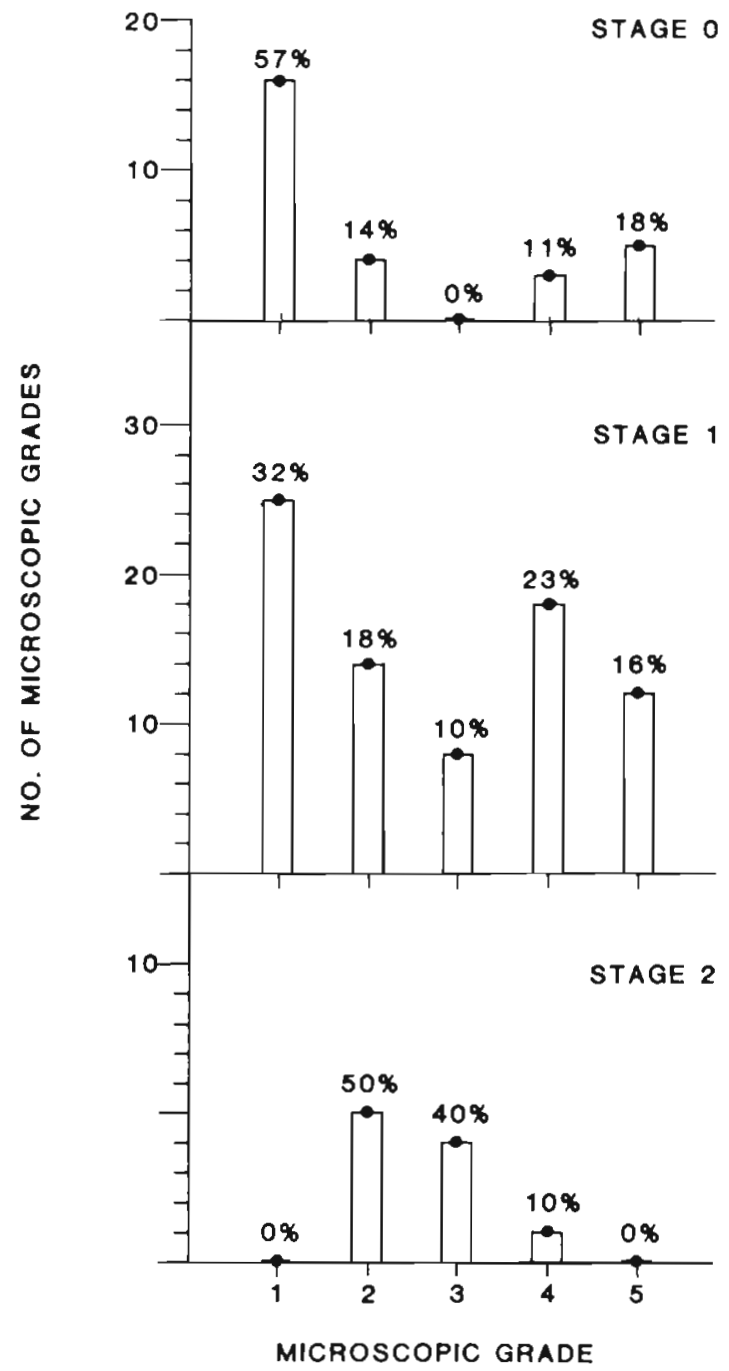

Fig. 3. Clinocardium nuttallii. Distribution of 3 visual stages over the 5 microscopic grades. The follicles of each sex were considered separately so the minimum number of grades assigned to a cockle was 2 . Since a cockle could contain follicles with several grades, the upper limit was 10 grades (5 per sex). Stage $0, n=11, m=28$; Stage $1, n=28, m=77$; Stage $2, n=6, m=20(n=$ number of cockles, $m=$ number of microscopic grades assigned to a stage)

attached but many were undergoing karyolysis and cytolysis. Male: The follicle was collapsed with some residual spermatozoa present in the lumen, and some spermatids were attached to the wall.

\section{Grade 5 - Post spawning-recovery}

(Fig. 2f)

At this stage is it difficult to distinguish the sexes. Follicles were collapsed. Rare residual spermatozoa and oocytes served to identify the sex of the follicle. Pigmented cells were present.

\section{Microscopic Grades, Visual Stages and Size}

The relationship between the visual and the microscopic grades is shown in Fig. 3. Stage 0 predominantly corresponds to the microscopic grade of 1 , viz., the early, developing stage. Stage 2 predominantly corresponds to Grades 2 and 3, viz., the pre-spawning and mature conditions. Stage 1 was assigned to cockles later graded ranging from 1 to 5 and therefore did not provide useful information about the maturity of the gonad.

Cockle size and visual stage (257 samples) are related as follows: Stages 0 and 1 are represented

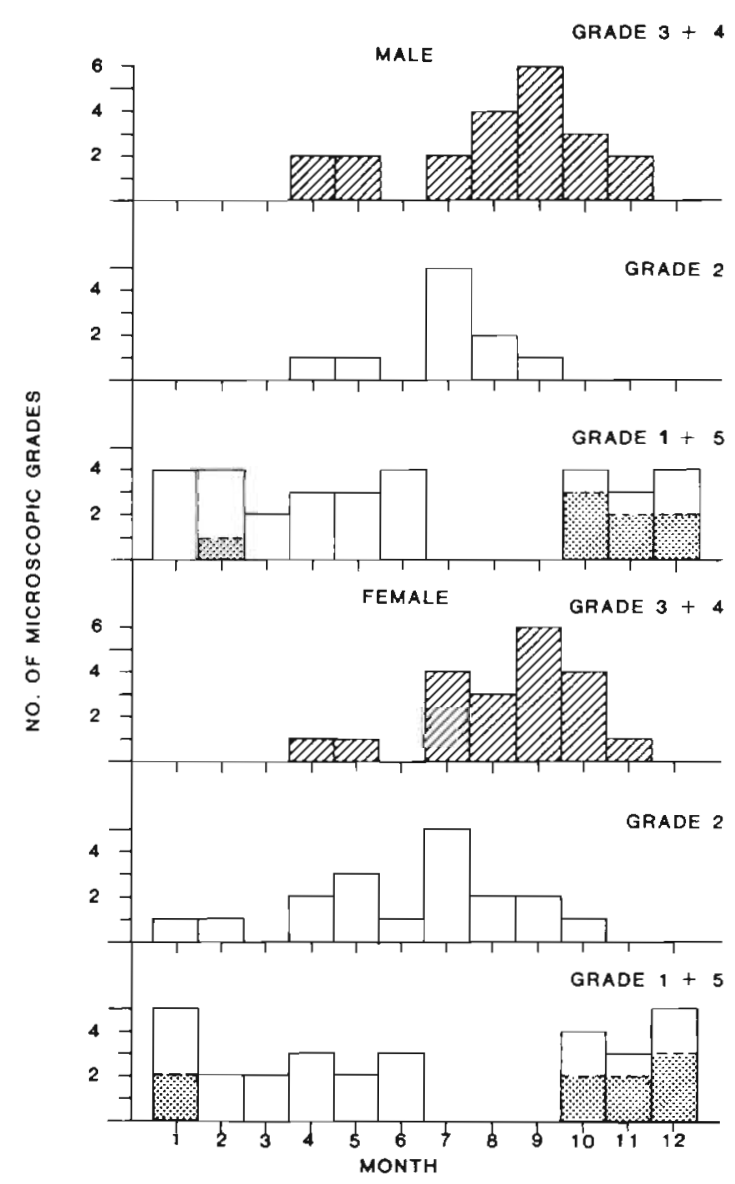

Fig. 4. Clinocardium nuttallii. Distribution of grades of male and female follicles by month. Since follicles of each sex were considered separately and there are 5 different microscopic grades, each sample may contain up to 10 possible grades ( 5 per sex), but usually there were no more than 2 grades per sex. Graphs of Grades 3 and 4 are shaded to emphasize the distribution of ripe and just spawned follicles. For Grades 1 and/or 5 the height of the cross-hatched areas represents the number of Grade 5 . In no month is the whole sample shaded, indicating that whenever a Grade 5 occurred Grade 1 follicles were also found 
across all size classes; Stage 2, the mature or ripe cockle, however, is not represented by any cockles less than $50 \mathrm{~mm}$ (the maximum size for one year's growth) for any month, tidal height, or region of the bay.

\section{Gonadal Change by Month and Area}

The pooled data for all 3 areas of the bay (257 cockles) shows that Stage 2 (most ripe) occurs 41 times from April to September, and in no other months. The pooling over the areas is acceptable because Chisquare tests indicate no statistically meaningful relationship between gonad stages and area.

Examination by simple presence or absence of a given stage (rather than a statistical analysis dependent on the relative number) in different areas reveals however, that Stage 0 cockles occur in the sandy (open) north area as late as July, whereas no Stage 0 cockles occur in the silt/clay (closed) south area after May.

The relationship between microscopic grades and month is given in Fig. 4 for male and female follicles separately. Grades 1 and 5 are pooled since Grade 1 describes the earliest stages of gametogenesis and Grade 5 the last stages. In either case, the gonad is essentially devoid of developed gametes. In July, August, and September neither male nor female follicles occurred, with Grades of 1 or 5. Grade 2, which corresponds to developing pre-mature gonads, is mostly found over the period from April to October. Grades 3 and 4 are pooled since Grade 3 describes the mature gonad and Grade 4 the early post-spawning condition. In either case, Grades 3 and 4 are indicators of the time of spawning. The period of spawning is from April to November (Fig. 4), but the weight of the distribution is from July to September. No mature follicles were found in June.

\section{DISCUSSION}

\section{Months of Spawning}

Mature or just spawned gonads of Clinocardium nuttallii - viz. Grades 3 and 4 respectively - occur from April to November (Fig. 4). Grade 5, which corresponds to a post-spawning or recovery state, occurs only from October to February; Grade 1, which corresponds to the initiation of gametogenesis, occurs from January to June, and from October to December. Recall that male and female gametes are almost always in the same grade in any gonad (Fig. 4). Further, in any gonad there frequently are gametes of the same sex with different grades, although these grades are always sequential.

These facts suggest that spawning occurs from April to November, the recovery state from October to February, and gametogenesis from October to June. The earliest month for initiation of gametogenesis is October and the earliest month for spawning is April, covering a period of 7 months. The latest month for gametogenesis is June and the latest month for spawning is November - a period of 6 months.

Examination of the central tendencies of the distribution for males and females in Fig. 4 indicates that 'an average cockle' spawns over a period centered in July-August, has a rest state over a period centered in November-December, and initiates gametogenesis over a period centered in February-March.

Another interpretation of the data in Fig. 4 is that some fraction of the population spawns twice a year (an October spawning cockle could potentially spawn again 7 months later in April). The pooled distribution of male and female gametes of Grades 3 and 4 indicates, however, that the tails - April and November spawners - are a relatively small segment of the population, which is all we know about the possibility of 2 reproductive cycles per year.

Samples from Garrison Bay in November typically show many cockles at $5 \mathrm{~mm} \pm 1 \mathrm{~mm}$ and February samples show cockles at $15 \mathrm{~mm} \pm 1 \mathrm{~mm}$. Backward projection on a cockle growth curve based on growth experiments (Gallucci and Geiszler, in preparation) established an autumn spawning, independent of the gonadal analyses. Although variations between a single ejaculate spawning and protracted spawning over a period of several months are possible under the once a year scenario, it is unlikely that a re-initiation of gametogenesis occurs in the summer months. Neither Grades 1 nor 5 are found over a 3 month period centered in August.

Of the 33 samples examined both visually and microscopically in June, in 2 successive years, no mature gonads were ever found in that month. The trend in the stages and grades of mature gonads before and after June, and the distribution of associated microscopic Grade 2 suggests however, that the complete absence of ripe gonads in June is a sampling artifact. Nevertheless, further study might reveal that the absence of mature cockles in June implies a minor spawning peak in April and May with the major spawning from July to September (Fig. 4, Grades $3+4$ )

Perhaps the reason that the Pacific cockle's checks or growth lines are known to be unreliable for aging purposes (false checks) is a consequence of a spawning period that extends over $2 / 3$ of the year and an existence at the sediment surface which accentuates the impact of environmental fluctuations. 


\section{Size at First Spawning}

Clinocardium nuttallii dwell at or just below the sediment surface. In Garrison Bay there is a well defined intertidal zonation by size with the larger cockles at the lower levels (Gallucci and Sayce, submitted). Predation by gulls (Larus glaucescens) during daylight low tides, combined with crab (Cancer productus and $C$. gracilis) and flatfish (primarily of the family Pleuronectidae) predation on the smaller sizes the gulls do not take, removes most of the larger cockles from the middle levels by autumn. This occurs despite apparently uniform recruitment in the mid to low tidal levels (Gallucci and Geiszler, in preparation).

The growth of cockles is correlated with the tidal level and the area in Garrison Bay. The size ranges corresponding to growth after 1,2 and 3 yr of growth are:

Years of growth $\quad 1 \quad 32$

Size range $(\mathrm{mm}) \quad 34.3-50.3 \quad 54.0-69.5 \quad 65.4-76.8$

These growth rates were computed by fitting a von Bertalanffy growth model and predicting size at age for the different areas of Garrison Bay. Optimal growth, in the lower intertidal and closed area of the bay, is $50 \mathrm{~mm}$ in $1 \mathrm{yr}$. However, measurement of growth rate is complicated by the extended period of spawning. Cockles that set in the early summer from spring spawners grow more quickly, especially in a warm spring, than cockles that result from autumn spawners (Gallucci and Geiszler, in preparation). For this reason we have found it preferable to interpret reproductive data in terms of size and to use the growth curve for the probable age.

The length at first spawning is the shortest length at which a full gonad (visual Stage 2) or mature follicles (microscopic Grade 3) first occurs. In the 257 staged cockles, Stage 2 occurred 41 times. Of these only 2 were less than $51 \mathrm{~mm}$ (50.1 and 50.7) long. The smallest cockle to be assigned a corresponding microscopic grade of 3 (mature follicles) was $55.9 \mathrm{~mm}$ in length. Since $50 \mathrm{~mm}$ was the approximate maximal size after $1 \mathrm{yr}$, it is likely that Clinocardium nuttallii in Garrison Bay occasionally spawn in the first year. Small cockles with ripe gonads could then be first-year animals, e.g. the progeny of early spring spawners.

Given the heavy regimen of predation and the relatively low proportion of smaller cockles with ripe gonads, the possibility of an optimal size at first reproduction arises. For example, the growth strategies of Cardium edule (European cockle) and the mussel Modiolus modiolus differ (Seed and Brown, 1978). The mussel has a size refuge from predation and puts all its energy into growth for 4 to $6 \mathrm{yr}$ and then becomes reproductive. However, $C$. edule rarely survives predation past the third year and becomes reproductive in the second year. The wide spawning interval of Clinocardium nuttallii makes exact comparison difficult, but unlike the European cockle, C. nuttallif shows evidence of bisexual reproductive development even in the first year, and at least the potential to spawn. Further, there is no refuge in size for C. nuttalIii, so the growth strategy is very rapid growth out of the range of fish and crab predators into the size range of gull predation where the probability of survival is increased at the lower tidal levels

\section{Visual Stage and Microscopic Grade}

There are many reasons one might wish to determine the spawning condition of an animal from visual examination of the gonadal mass. This is easier to do with accuracy in mussels (Suchanek, 1979) and in scallops (Dickie, 1955) because the gonads of these bivalves form discrete masses. In clams such as Clinocardium nuttallii the gonad is surrounded by the musculature of an unusually large and powerful foot; hence body tissues interfere with the assignment of a unique macroscopic stage. Microscopic grades facilitate a finer distinction of the developmental sequence. Since Stages 0 and 2 were the most meaningful (Fig. 3) we suggest that it is best to use a binary system of staging to assess gonadal development in $C$. nuttallii.

\section{Hermaphroditism and Reproductive Strategy}

The classical 'low density model' (Ghiselin, 1969; Charnov et al., 1976) is one of the most popular explanations for the evolution of a bisexual mode of reproduction. Low density, low animal mobility, and possible depopulations associated with unstable environments are all considered to favor the evolution of simultaneous hermaphroditism. In addition to the simultaneous hermaphrodite Clinocardium nuttallii, the bivalve community in Garrison Bay also contains a sequential hermaphrodite, Transennella tantilla. All of the other bivalves are dioecious. Thus, it may be useful to consider what these 2 bivalves have in common with respect to the 'low density model'.

Transennella tantilla is a sequential hermaphrodite, first male and then female (protandric), broods its young, and never reaches $10 \mathrm{~mm}$ in size. Populations occur at the sediment surface in very dense aggregations in spring and summer. During low tide they are found under mats of the alga Enteromorpha intestinalis, where they are protected from summer dessication, but when the tide rises Enteromorpha floats, exposing the bivalves. In a similar way, temperature extremes in both summer and winter also cause cockle 
mortality. Unpublished experiments with temperatures between $35^{\circ} \mathrm{C}$ and $-5^{\circ} \mathrm{C}$ show differential mortality with cockle size, with cockles under $10 \mathrm{~mm}$ experiencing decreased rates of mortality.

Since both bivalves occur at the sediment surface and do not burrow deeper as they grow, they are subject to predation from both searching and from unselective feeders. Transennella tantilla has been found in the guts of juvenile flatfish and crabs in Garrison Bay and in the feces of the deposit feeding clam Macoma nasuta (Hylleberg and Gallucci, 1975). Clinocardium nuttallii, as noted, endures vigorous predation (by crabs, flatfish, and gulls). Thus, unlike the other bivalves, neither hermaphrodite attains a size where the level or intensity of predation tapers off, i.e. there does not exist an optimal growth strategy to guide the allocation of energy between growth and reproduction.

Although low density is considered a possible factor in the evolution of hermaphroditism, density should be considered in terms of spatial pattern and not simply number per square unit. For example, patterns such as swarms, schools and clumps have been given many rationales, one of which is usually the facilitation of reproductive success. The determination of pattern for Clinocardium nuttallii is, however, complicated by the rapid decrease in cockle density at all but the lowest tidal levels, as the autumn approaches. Only at these low levels is there evidence for a clustered distribution. At the higher tidal levels one might also argue that under intense gull predation clustered cockles would be more easily located than dispersed individuals. In all, neither density nor pattern appears to conform to the requirements of the low density model, especially since clumps of sexually mature cockles are found in the location (low intertidal) most sheltered from gull predation.

The second factor usually associated with the low density model is that of a sessile existence. Migration experiments in Garrison Bay with cockles show that they do not migrate (Gallucci and Sayce, submitted), but laboratory experiments with cockles and seastars show that cockles have a consistent well-defined escape response (pers. obs.). In addition, Transennella tantilla is adequately small, especially at birth, to be carried by water currents and appears capable of limited migration (Gallucci and Kawaratani, 1975). Among the bivalves most known for hermaphroditic reproduction are scallops (very mobile) and oysters (immobile), to which we add cockles (potentially mobile), $T$. tantilla (small enough to be carried by currents). Thus, sessileness in bivalves would not appear to be a contributory factor in the evolution of the mode of reproduction.

We conclude that in Garrison Bay hermaphroditic reproduction is primarily linked to life at the sediment surface. There, it is a convenient prey without a growth strategy to provide a size refuge for sexually mature individuals. Furthermore, at the surface, fluctuations and extremes of weather cause mortality at far greater levels than upon corresponding mature individuals of dioecious, burrowing bivalves.

Acknowledgements. The authors are grateful to J. Hansen, $M$. Kyte and C. Sheehan for the collection of field samples in 1975-1976, to R. Rath for the processing of microscopic samples, and to A. O. D. Willows and E. Kozloff, Directors of the Friday Harbor Laboratories, for the use of excellent Iaboratory facilities. The Superintendent of the San Juan National Historical Monument of the National Park Service, Z. Zachwieja (ret.), and the Assistant Director of the Washington State Department of Fisheries, Shellfish Program, C. Lindsay (ret.) facilitated our access to Garrison Bay and contributed in many ways toward making a long term research program possible in Garrison Bay. N. Bourne, R. Fernald, D. Geiszler, E. Kozloff and J. Orensanz critically read the manuscript and offered useful discussion of many parts. D. Geiszler also helped with many of the computations. The Washington Sea Grant Program under the Garrison Bay Studies Project provided the funds to make this research possible (Project $R / F$ 38, Grant No. NA81AA-D-00030 from the National Oceanic and Atmospheric Administration)

\section{LITERATURE CITED}

Bawa, K. S. (1980). Evolution of dioecy in flowering plants. Ann. Rev. Ecol. Syst. 11: 15-39

Boyden, C. R. (1971). A comparative study of the reproductive cycles of the cockles Cerastoderma edule and C. glaucum. J. mar. biol. Ass. U. K. 51: 605-622

Charnov, E. L., Smith, J. M., Bull, J. J. (1976). Why be a hermaphrodite? Nature, Lond. 263: 125-126

Dickie, L. M. (1955). Fluctuations in abundance of the giant scallop. Placopecten magellanicus (Gmelin), in the Digby area of the Bay of Fundy. J. Fish. Res. Bd Can. 12: 797-857

Edmondson, C. H. (1920). Edible mollusca of the Oregon coast. Pap. Bernice P. Bishop Mus polynesian Ethnology and nat. Hist. 7 (9) : 179-208

Elliott, J. M. (1971). Some methods for the statistical analysis of samples of benthic invertebrates. Freshwater Biological Association, The Ferry House, Westmorland, England

Fraser, C. M. (1931). Notes on the ecology of the cockle, Cardium corbis (Martyn). Trans. R. Soc. Can. 5: 59-72

Gallucci, V F., Kawaratani, R. (1975). Mortality of Transennella tantilla due to burial. J. Fish. Res. Bd Can. 32 $1637-1640$

Gallucci, V F., Geiszler, D. R. (in preparation). Population dynamics of the cockle (Clinocardium muttallii) in Garrison Bay

Gallucci, V F. Rawson, C. B. (1979). The population dynamics and management modeling of harvested bivalves in Garrison Bay, Washington. Available on interlibrary loan from the University of Washington Library, Seattle, Washington

Gallucci, V F., Sayce, J. (submitted). The roles of switching by an avian predator and size selective mortality in the stability of intertidal zonation

Ghiselin, M. T (1969). The evolution of hermaphroditism 
among animals, Q. Rev. Biol. 44: 189-208

Hylleberg, J., Gallucci, V. F. (1975). Selectivity in feeding by the deposit-feeding bivalve Macoma nasuta. Mar Biol. 32: $167-178$

Kingston, P. F. (1974). Studies on the reproductive cycles of Cardium edule and C. glaucum. Mar. Biol. 28: 317-323

Quayle, D. B. (1960). The intertidal bivalves of British Columbia, British Columbia Provincial Museum, Canada

Quayle, D. B., Bourne, N. (1972). The clam fisheries of British Columbia. Bull. Fish. Res. Bd Can. 179

Rygg, B. (1970). Studies on Cerastoderma edule L. and Cerastoderma glaucum (Poiret). Sarsia 43: 65-80

seed, R., Brown, R. A. (1978). Growth as a strategy for survival in two marine bivalves, Cerastoderma edule and Modiolus modiolus. J. Anim. Ecol. 47-283-292

Scherba, S., Jr., Gallucci, V F. (1976). The application of systematic sampling to a study of infaunal variation in a soft substrate environment. Fish. Bull. U. S. 74: 937-948

Suchanek, $T H$., Jr (1979). The Mytilus californianus community: studies on the composition, structure, organization, and dynamics of a mussel bed. Ph. D. dissertation, University of Washington

Rawson, C. B. (1980). Scales of spatial patterns of the clams Protothaca staminea (Veneridae) and Macoma nasuta (Tellinidae) in Garrison Bay. M. S. thesis, University of Washington

This paper was submitted to the editor; it was accepted for printing on November 2, 1981 